\title{
BMJ Global Health One hundred thirty-three observed COVID-19 deaths in 10 months: unpacking lower than predicted mortality in Rwanda
}

Clarisse Musanabaganwa (D , , ${ }^{1}$ Vincent Cubaka, ${ }^{2}$ Etienne Mpabuka, ${ }^{1}$ Muhammed Semakula, ${ }^{1}$ Ernest Nahayo, ${ }^{3}$ Bethany L Hedt-Gauthier, ${ }^{4}$ Kamela C S Ng, ${ }^{4}$ Megan B Murray, ${ }^{4}$ Fredrick Kateera, ${ }^{2}$ Leon Mutesa (D) , Sabin Nsanzimana ${ }^{1}$

To cite: Musanabaganwa C, Cubaka V, Mpabuka E, et al. One hundred thirty-three observed COVID-19 deaths in 10 months: unpacking lower than predicted mortality in Rwanda. BMJ Global Health 2021;6:e004547. doi:10.1136/ bmjgh-2020-004547

Handling editor Seye Abimbola

Received 24 November 2020 Revised 22 January 2021 Accepted 26 January 2021
Check for updates

(c) Author(s) (or their employer(s)) 2021. Re-use permitted under CC BY-NC. No commercial re-use. See rights and permissions. Published by BMJ

For numbered affiliations see end of article.

\section{Correspondence to} Clarisse Musanabaganwa; clarisse.musanabaganwa@ gmail.com and Professor Leon Mutesa Imutesa@gmail.com

\section{ABSTRACT}

The African region was predicted to have worse COVID-19 infection and death rates due to challenging health systems and social determinants of health. However, in the 10 months after its first case, Rwanda recorded 10316 cases and 133 COVID-19-related deaths translating to a case fatality rate (CFR) of $1.3 \%$, which raised the question: why does Rwanda have a low COVID-19 CFR? Here we analysed COVID-19 data and explored possible explanations to better understand the disease burden in the context of Rwanda's infection control strategies. We investigated whether the age distribution plays a role in the observed low CFR in Rwanda by comparing the expected number of deaths for 10-year age bands based on the CFR reported in other countries with the observed number of deaths for each age group. We found that the age-specific CFRs in Rwanda are similar to or, in some older age groups, slightly higher than those in other countries, suggesting that the lower population level CFR reflects the younger age structure in Rwanda, rather than a lower risk of death conditional on age. We also accounted for Rwanda's comprehensive SARS-CoV-2 testing strategies and reliable documentation of COVID-19-related deaths and deduced that these measures may have allowed them to likely identify more asymptomatic or mild cases than other countries and reduced their reported CFR. Overall, the observed low COVID-19 deaths in Rwanda is likely influenced by the combination of effective infection control strategies, reliable identification of cases and reporting of deaths, and the population's young age structure.

\section{INTRODUCTION}

On 14 March 2020, Rwanda reported the first confirmed case of SARS-CoV-2, an asymptomatic traveller who arrived in Kigali on 8 March, presented with symptoms on 13 March and tested positive the following day. Like much of the world, Rwanda braced for the challenge ahead, expecting that without
Summary box

High numbers of deaths were expected in Rwanda and the rest of the African region due to insufficient capacity of health systems, challenging living conditions and vulnerable populations.

- The age-specific case fatality rates (CFRs) in Rwanda are similar to or, in some older age groups, slightly higher than those in other countries, suggesting that the lower population level CFR reflects the younger age structure in Rwanda, rather than a lower risk of death conditional on age.

- Rwanda employs comprehensive and diverse SARS CoV-2 testing strategies and are identifying most cases in the country, closely monitoring confirmed COVID-19 cases and reliably documenting COVID19-related deaths.

- The observed low COVID-19 CFR in Rwanda is likely influenced by the combination of effective infection control strategies, reliable identification of cases and reporting of deaths, and the population's young age structure.

- Rwanda, and Africa more broadly, should sustain data-driven COVID-19 control strategies to minimise the resulting deaths and morbidity from COVID-19.

implementing intensive distancing measures, it would experience a rapidly spreading epidemic and subsequent deaths. Many observers predicted that Rwanda, along with other African countries, would experience an even more devastating pandemic than had occurred in the Europe and the USA, citing insufficient capacity of health systems, comorbidities and overcrowded housing conditions as factors that were expected to impact both infection and death rates. ${ }^{1-5}$

However, in the 10 months after its first case, Rwanda recorded only 133 COVID-19-related deaths, which raises the question: why have 
there been so few COVID-19-related deaths in Rwanda in particular and Africa at large? Here we explore possible explanations with the goal of better understanding Rwanda's COVID-19 burden and mortality and the country's response.

\section{ARE CASES, OR MORE SPECIFICALLY DEATHS, BEING MISSED?}

One possible explanation for the low number of COVID19-related deaths is simply that these deaths are being missed. ${ }^{6}$ This seems highly unlikely, given Rwanda's extensive testing, ${ }^{7}$ both of suspected cases and contacts of cases and through random community sampling. Rwanda initiated SARS-CoV-2 infection testing using real-time PCR (RT-PCR) in February 2020; at first, SARS-CoV-2 testing was centralised at the National Reference Laboratory, ${ }^{8}$ which tested between 1000 and 1500 samples daily. Over the last 10 months, testing capacity has been decentralised-first expanding to four main public laboratories, three in Kigali and one in Southern Province, and then to seven additional sites in the Northern and Eastern Provinces. As of 14 January 2021, 506 health centers, and 52 district, provincial, and referral hospitals, spread across all five provinces, are equipped for SARS-CoV-2 sample collection and testing (11 of which were employing RT-PCR and the rest COVID-19 rapid tests). In our recent study, we describe the innovative pooled testing used at some sites in Rwanda to increase the capacity and efficiency of this testing. ${ }^{9}$ An average of 251 tests per million individuals are conducted daily, as compared with 76, 91, 2413, 4020 and 5183 per million in Kenya, Nigeria, Italy, Spain and the USA, respectively. ${ }^{10}$

Seven tertiary and all 37 district hospitals in Rwanda, along with 6 additional designated testing sites, have staff capable of performing clinical screening and collecting samples/testing suspected cases or contacts of confirmed cases, defined as anyone reported to have been within $1 \mathrm{~m}$ of the confirmed case for more than 1 min or participants in social events like marriage ceremonies and government meetings. Both groups wait in isolation at home until their result is available, usually between 8 and 24 hours. Rwanda also screens people entering the country at land borders and airports, including returning citizens and residents and truck drivers. These individuals are housed at quarantine sites near the point of entry for 24 hours while they await results. From July 2020, Rwanda began random testing, with individuals sampled from roadways (passengers of cars, buses or motorcycles or pedestrians), markets or communities where a cluster of cases have been identified. These individuals are screened for symptoms and provide samples on the spot and then receive their results via text message within 8 and 24 hours. As of 14 January 2021, 779511 SARS-CoV-2 tests have been performed (5951/100 000), of which $10316(1.3 \%)$ were positive (figure 1).

Confirmed cases were then closely tracked. Early in the epidemic, all diagnosed patients were followed up in isolation centres until they were confirmed to be SARS-CoV-2

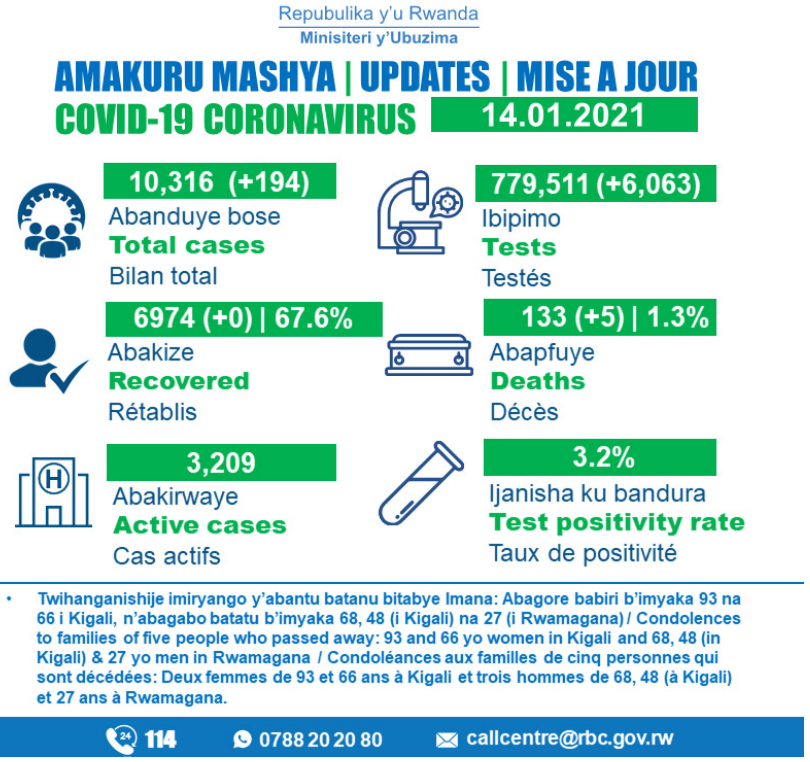

Figure 1 COVID-19 updates from the Rwanda Ministry of health published on 14 January $2021 .^{33}$

negative, with tests repeated 7 days later and again at 14 days, if necessary. Severe cases were managed in intensive care units established in specialised COVID-19 treatment centres; deaths in these patients were immediately reported to the national COVID-19 task force. In August 2020, individuals with mild disease symptoms were allowed to isolate at home by following the country's home-based COVID-19 management protocol, where a presumptive patient is screened from home, then the rapid response team visits to assess the capacity to undertake self-isolation at home (ie, sanitation facility, access to vital services, and availability of food and clean water). All patients confirmed with COVID-19 who meet the requirements for self-isolation as per the home-based COVID-19 protocol remained in contact with the health providers on a daily basis and were tested via RT-PCR on regular intervals until they recovered. Patients with progressing symptoms were accompanied to the treatment centre and admitted to the intensive care unit as deemed necessary. Patients sent home were provided with a Global Positioning System tracker to detect any social contact.

The comprehensive and diverse testing strategies suggest that most cases in Rwanda have been identified. The close monitoring of cases ensures that COVID-19 deaths are well documented.

\section{ARE RWANDA'S INFECTION CONTROL STRATEGIES TO CREDIT?}

Rwanda's low death rate may reflect its relatively low incidence rate. The 10316 confirmed cases recorded nationally in the first 10 months corresponds to a rate of 79 per 100000 people compared with 7 in China, 3874 in Italy, 4727 in Spain, 139 in South Korea or 7042 in the USA as of 14 January $2021 .^{11}$ As mentioned previously, we believe 
Rwanda is more likely to identify and document cases, including asymptomatic cases, because of the systematic contact tracing efforts and random population-level antigen testing. Therefore, these lower documented case rates and the $1.3 \%$ test positivity rate (cumulative positive tests per total test rate) indeed likely reflect lower numbers of infections overall.

How has Rwanda kept the number of SARS-CoV-2 infections so low? First, the infection arrived in Africa months after first reports in China and considerably later than most of Asia and Europe. This allowed for immediate countrywide lockdown measures and for Rwanda to draw from the lessons, experiences and best practices from the countries that had been affected earlier in the pandemic. Rwanda was also well prepared for this pandemic, having built comprehensive infection control plans in the wake of the Ebola epidemic in 20132015. These measures included intensive monitoring at borders. Because neighbouring states were on high alert for new Ebola outbreaks, health screening of travellers was already in place for Ebola in March 2020, and this was easily extended to include screening for SARS-CoV-2.

In addition to being able to model off of other countries' experiences, Rwanda's distancing and infection control strategies have been decisive, data-driven and enforced. Further, there is broad population buy-in for the government strategies. The country closed her borders to international flights on 21 March 2020. ${ }^{12}$ The in-country containment strategies, first outlined by the Office of the Prime Minister on 1 April 2020, ${ }^{13}$ banned public gatherings; closed schools, restaurants, bars, gyms and churches; and required non-essential public and private employees to work from home. Unnecessary movements were prohibited and only single-passenger motorbikes were permitted for public transport. These containment policies were complemented with mass release of Rwanda-specific health communication tools (figure 2) to educate the public about the COVID-19 modes of transmission and to encourage wearing face masks (which was nationally mandated on 19 April 2020), hand washing, avoiding handshakes and social distancing of at least $1 \mathrm{~m} .{ }^{14}$

Although the lockdown succeeded to contain COVID-19 spread in Rwanda, it also negatively affected the socioeconomic and health sectors. This led to partial

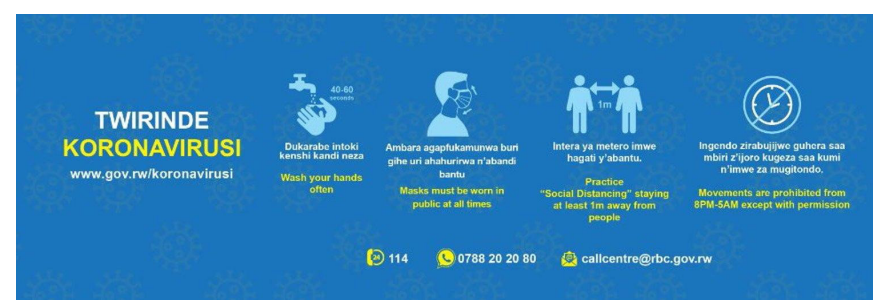

Figure 2 Public health communication tool disseminated in Rwanda to encourage measures against the infection and spread of COVID-19-hand washing, wearing face masks, social distancing of at least $1 \mathrm{~m}$ and restricted mobility. ${ }^{14}$ lifting of lockdown on 16 June $2020^{13}$; the new policy allowed traders to work (encouraging digital payments where possible), permitted some movements during the day (05:00 to 21:00), and approved wedding ceremonies and burial ceremonies with less than 30 persons. ${ }^{14}$ In parallel, the government installed public handwashing stations at markets, bus stations and other congested places with population mixing. As of 14 December 2020, all in-person gatherings, including wedding ceremonies, have been prohibited. ${ }^{15}$ The government continues to closely monitor COVID-19 testing and case clusters, intensifying or relaxing the national mandates based as necessary.

Given that $83 \%$ of the Rwandan population is living in rural areas ${ }^{16}$ and $80 \%$ of households are engaged in agricultural work, ${ }^{17}$ it is likely that many Rwandan families could continue most agricultural activities unabated, with little need for interactions that would increase COVID-19 infection risk. This natural societal isolation also permitted broader relaxing of the national distancing strategies, particularly when complemented with focused interventions when outbreaks emerge. As an example, when national distancing strategies were relaxed, a stricter set of measures were executed at the Rusizi and Rusumo border crossing, as most cases in Rwanda during the lockdown were linked to truck drivers crossing at those borders. ${ }^{18}$ Now, when case clusters are identified, strict distancing measures are implemented in those small areas rather than regionally or nationally.

\section{ARE COVID-19 CASE FATALITY RATES (CFRS) LOWER IN RWANDA?}

Rwanda registered its first COVID-19 fatality on 30 May 2020, and by 14 January 2021, 133 COVID-19 deaths have been recorded in the country (figure 1). This translates to a CFR of $1.3 \%$, notably lower than the estimated $2.8 \%$ CFR in South Africa, $1.4 \%$ in Lesotho, $1.7 \%$ in the USA, $2.4 \%$ in Spain, $4.9 \%$ in China, $1.5 \%$ in Ireland or $3.5 \%$ in Italy. ${ }^{19}$ We considered several different hypotheses to explain the COVID-19 low CFR.

First, because of Rwanda's extensive testing efforts, the country has likely identified more cases, and specifically more asymptomatic or mild cases, than many other countries. This inflates the denominator, particularly with less sick and lower-risk individuals, and reduces the reported CFR.

Second, it is possible that previous widespread viral exposure provided acquired immune protection against severe COVID-19 disease. ${ }^{20}{ }^{21}$ Cross-reactive $\mathrm{T}$ cells have been found in individuals who have not been exposed to SARS-CoV-2, suggesting previous exposure to related human coronaviruses could generate immunological cross-reactivity. ${ }^{20} \mathrm{~A}$ study on whether respiratory infections that occurred in December 2019-January 2020 in Kinshasa, Democratic Republic of the Congo, may have been caused by the 'common cold' coronavirus OC42 that may have generated antibodies and cross-reacted 
and neutralised SARS-CoV-2 is under way. ${ }^{22}$ Suggestions of previous exposure to coronaviruses in the region and their possible protective features are not well substantiated; studies in Rwanda and the region are exploring these hypotheses.

A third hypothesis is that Rwanda has a lower prevalence of comorbidities associated with poor COVID-19 outcomes. Among a sample of 1174 patients who were treated at two isolation centres near Kigali in the first 6 months, $12.4 \%$ had an underlying non-communicable disease-of these, $46.9 \%$ had hypertension; $31.7 \%$ had diabetes; $14.6 \%$ had heart disease; and $13.8 \%$ had asthma-and this non-communicable disease distribution is consistent with that observed in a retrospective cohort study in Wuhan, China. ${ }^{23}$ Another $4.8 \%$ of the Rwandan cases in these 1174 patients had communicable comorbidities, including $58.9 \%$ of these with HIV and $8.95 \%$ with tuberculosis.

A fourth hypothesis relates to some form of protection conferred by the genetic diversity in the host population in Rwanda. The work led by the COVID-19 Human Genetic Effort consortium ${ }^{20}$ is investigating whether human genetic factors are associated with severe COVID-19 disease.

Finally, and importantly, the age distribution in Rwanda likely plays an important role. Among the 1174 patients with COVID-19 enrolled in the two treatment centres in Kigali, $75.5 \%$ presented without symptoms. This proportion is consistent with global COVID-19 infections in younger populations being predominantly asymptomatic. $^{20} 21$ The risk of dying from COVID-19, as calculated from data in the UK, increases by $13 \%$ for every year of age, ${ }^{24}$ implying that a 60 -year-old is 100 times more likely to die than a 20-year-old. In Rwanda, only $5.1 \%$ of the population is over 60 years old,${ }^{25}$ in contrast with $20.5 \%-23.1 \%$ in the European Union. ${ }^{24}{ }^{26}$ Notably, age-specific CFRs in Rwanda are similar to or, in some older age groups, slightly higher than those in China, ${ }^{27}$ Italy, ${ }^{28}$ Spain ${ }^{19}$ and South Korea ${ }^{19}$ (table 1 and figure 3A), suggesting that the lower population level CFR reflects the younger age structure in Rwanda (figure 3B) rather than a lower risk of death conditional on age. We identified one paper reporting age-banded CFRs in another African country, Burkina Faso. ${ }^{29}$ The 15 -year age bands reported did not align with these other studies, limiting comparison; however, the approximately comparable age bands and the overall CFR of 5.7\% were considerably higher than the CFR of $1.3 \%$ observed in Rwanda. This comparison should be interpreted with caution, as the high CFR in Burkina Faso could reflect higher death rates or lower testing and identification of cases, or both.

\section{CONCLUSION}

There is no definitive explanation for the observed low COVID-19 mortality in Rwanda, and it is likely to be multifactorial. Other risk factors, such as population density and mobility, ${ }^{29} 30$ temperature and relative humidity, ${ }^{30} 31$ and a functional basis for heterologous

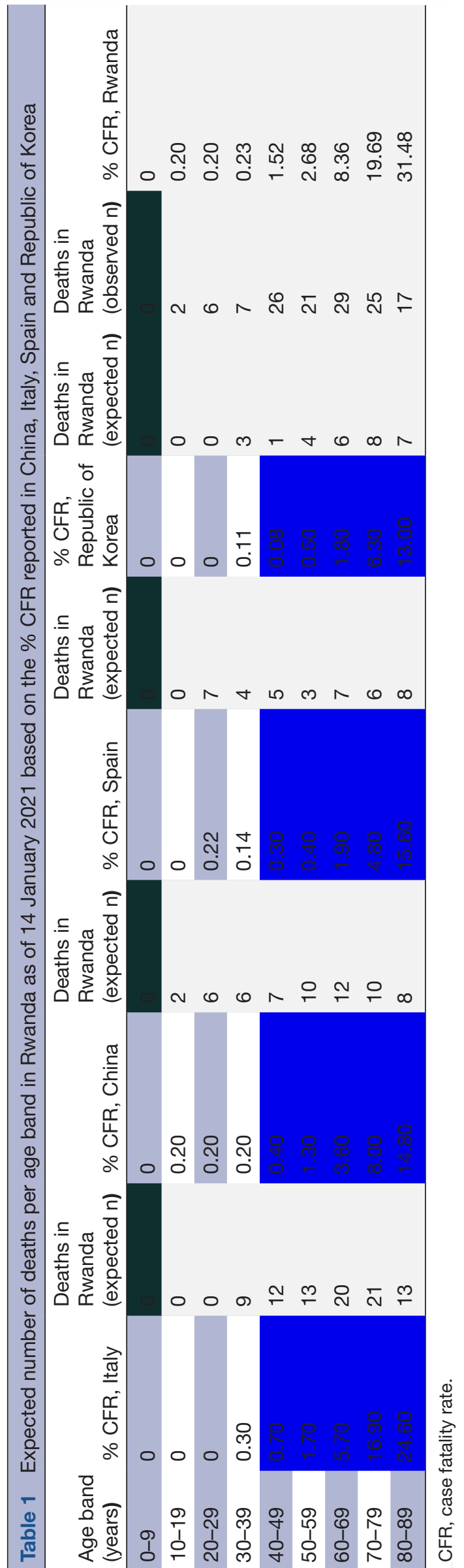



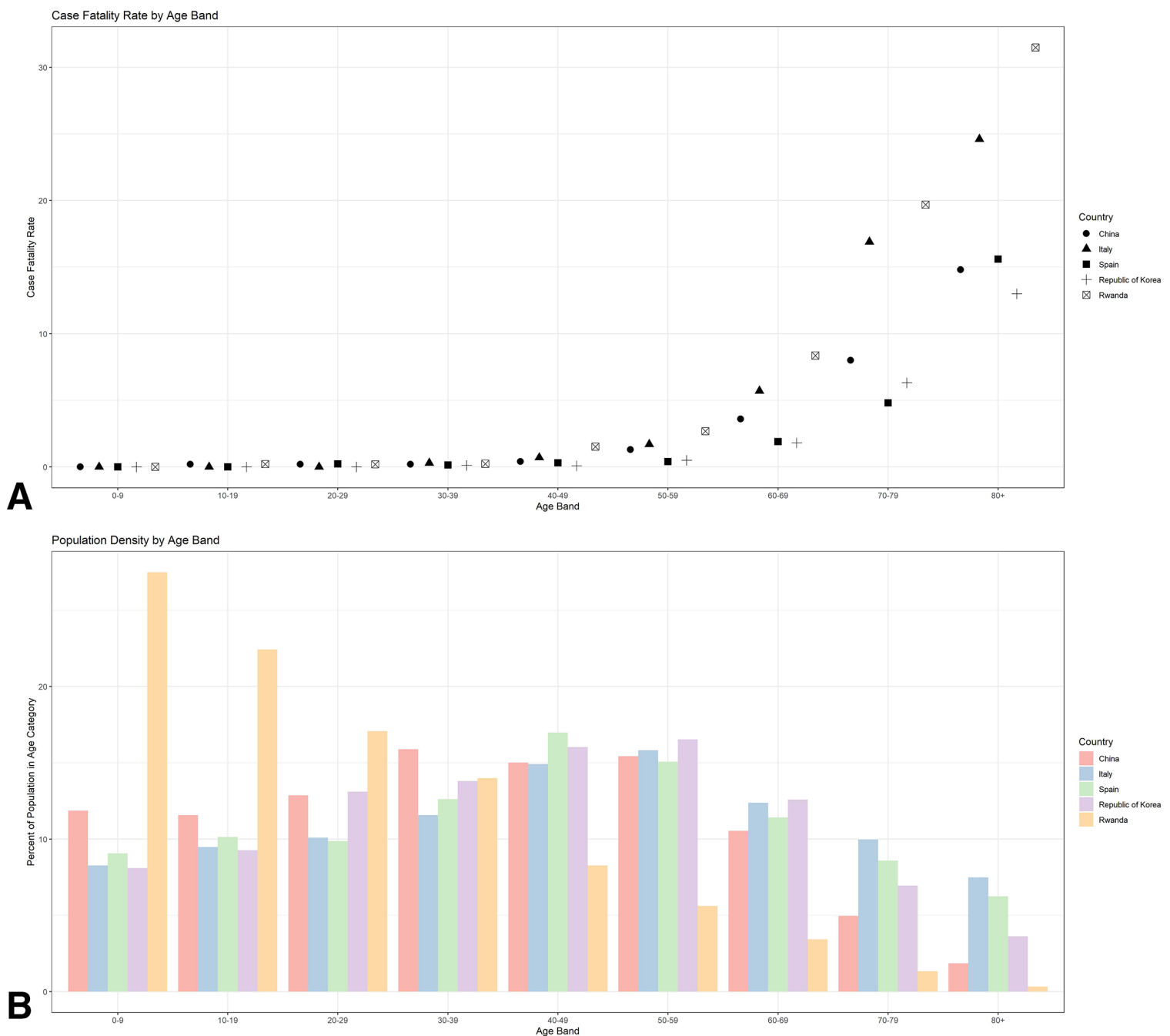

Figure 3 (A) Comparison of the COVID-19 case fatality rate by age band in Rwanda, China, Italy, Spain and Korea. (B) Comparison of the population density by age band in Rwanda, China, Italy, Spain and Korea.

immunity in SARS-CoV-2 infection, ${ }^{32}$ may be unique to Rwanda and/or other neighbouring countries and might influence SARS-CoV-2 transmission dynamics or morbidity. However, these theories, along with some others explored in this analysis, are not definitive and need further study.

Here we focus on contribution of the Rwandan government response- the curation of high-quality information on COVID-19 case and case fatality, the lessons learnt from these data about infection and mortality risk, and the use of these data to inform strategies to control transmission within the country-to limit COVID-19 infection and mortality. The strong testing and tracing strategies give us confidence in the mortality numbers from Rwanda. The strict infection control strategies have limited infections, and the young population structure decreases the risk of death among those infected. In the meantime, Rwanda, and Africa more broadly, should maintain datadriven prevention and response measures to minimise the resulting deaths and morbidity from COVID-19.

\section{Author affiliations}

${ }^{1}$ Medical Research Center, Rwanda Biomedical Center, Kigali, Rwanda
${ }^{2}$ Department of Research and Training, Partners in Health Rwanda, Kigali, Rwanda ${ }^{3}$ Rwanda Military Hospital, Kigali, Kigali City, Rwanda

${ }^{4}$ Department of Global Health and Social Medicine, Harvard Medical School, Boston, Massachusetts, USA

${ }^{5}$ Center of Human Genetics, University of Rwanda College of Medicine and Health Sciences, Kigali, Rwanda

Twitter Muhammed Semakula @semakulam

Contributors All authors have significantly contributed to the work, and have read and approved the manuscript.

Funding The authors have not declared a specific grant for this research from any funding agency in the public, commercial or not-for-profit sectors.

Competing interests None declared.

Patient consent for publication Not required.

Provenance and peer review Not commissioned; externally peer reviewed.

Data availability statement Data are available upon request.

Open access This is an open access article distributed in accordance with the Creative Commons Attribution Non Commercial (CC BY-NC 4.0) license, which permits others to distribute, remix, adapt, build upon this work non-commercially, and license their derivative works on different terms, provided the original work is properly cited, appropriate credit is given, any changes made indicated, and the use is non-commercial. See: http://creativecommons.org/licenses/by-nc/4.0/.

ORCID iDs

Clarisse Musanabaganwa http://orcid.org/0000-0002-9006-8310 
Leon Mutesa http://orcid.org/0000-0002-5308-3706

\section{REFERENCES}

$1 \mathrm{WHO}$, Regional Office for Africa. New WHO estimates. Up to 190000 people could die of COVID-19 in Africa if not controlled. Available: https://www.afro.who.int/news/new-who-estimates-190000-people-could-die-covid-19-africa-if-not-controlled [Accessed 26 Oct 2020].

2 The Lancet . COVID-19 in Africa: no room for complacency. Lancet 2020;395:1669.

3 Berhan Y. Will Africa be Devastated by Covid-19 as many predicted? perspective and prospective. Ethiop J Health Sci 2020;30:459-67.

4 El-Sadr WM, Justman J. Africa in the path of Covid-19. N Engl J Med 2020;383:e11.

5 Massinga Loembé M, Tshangela A, Salyer SJ, et al. COVID-19 in Africa: the spread and response. Nat Med 2020;26:999-1003.

6 The Economist. A million and not counting - Africa closes in on 1m reported cases of covid-19 | Middle East \& Africa. Available: https:// www.economist.com/middle-east-and-africa/2020/08/06/africacloses-in-on-1m-reported-cases-of-covid-19 [Accessed 12 Nov 2020].

7 Nachega JB, Grimwood A, Mahomed H, et al. From Easing Lockdowns to Scaling-Up Community-Based COVID-19 Screening, Testing, and Contact Tracing in Africa - Shared Approaches, Innovations, and Challenges to Minimize Morbidity and Mortality. Clin Infect Dis 2020:ciaa695.

8 Republic of Rwanda Ministry of Health, Rwanda Biomedical Centre. Coronavirus Disease 2019, National Preparedness and Response Plan [Internet]. Republic of Rwanda Ministry of Health, 2020. Available: https://moh.gov.rw/index.php?id=511 [Accessed $28 \mathrm{Jul}$ 2020].

9 Mutesa L, Ndishimye P, Butera Y, et al. A pooled testing strategy for identifying SARS-CoV-2 at low prevalence. Nature 2021;589:276-80.

10 Hasell J, Mathieu E, Beltekian D, et al. A cross-country database of COVID-19 testing. Sci Data 2020;7:345.

11 Coronavirus (COVID-19) Cases - Statistics and Research - Our World in Data [Internet]. Available: https://ourworldindata.org/covidcases [Accessed 26 Oct 2020].

12 VOA News. Rwanda Stops Domestic, Foreign Travel in Coronavirus Fight | Voice of America - English. VOA News, 2020.

13 Republic of Rwanda - Prime Minister Office: Cabinet Communiqué 1st April 2020. Available: https://www.primature.gov.rw/index. php?id=131\&tx_news_pi1\%5Bnews $\% 5 D=904 \& t x \_n e w s \_p i 1 \%$ 5Bcontroller\%5D=News\&tx_news_pi1\%5Baction\%5D=detail\& cHash $=a 064 a 986 d 8729$ e6d20b669a735009603 [Accessed 26 Oct 2020].

14 Ngirente E. Republic of Rwanda Office of the Prime Minister Statement on Cabinet Decisions of 2ndJune 2020 [Internet]. Republic of Rwanda Office of the Prime Minister, 2020. Available: https://www.primature.gov.rw/index.php?id=43 [Accessed 03 Jun 2020].

15 Ngirente E. Republic of Rwanda - Prime Minister Office: Cabinet Communiqué 14 December 2020 [Internet], 2020. Available: https:// www.gov.rw/fileadmin/user_upload/gov_user_upload/Publications/ Cabinet_Resolutions/Statement_on_Cabinet_Resolutions_of_14_ December_2020.pdf [Accessed 15 Dec 2020].
16 National Institute of Statistics Rwanda [Internet]. RPHC4 thematic report: population size, structure and distribution |. Available: http:// statistics.gov.rw/publication/rphc4-thematic-report-population-sizestructure-and-distribution [Accessed 12 Nov 2020].

17 National Institute of Statistics Rwanda. Agricultural household survey 2017. Available: https://www.statistics.gov.rw/publication/ agricultural-household-survey-2017 [Accessed 12 Nov 2020].

18 The New Times. RBC explains sharp increase in Covid-19 cases, calls for calm. Rwanda [Internet]. Available: https://www.newtimes. co.rw/news/rbc-explains-sharp-increase-covid-19-cases-calls-calm [Accessed 12 Nov 2020].

19 Mortality Risk of COVID-19 - Statistics and Research - Our World in Data [Internet]. Available: https://ourworldindata.org/mortality-riskcovid [Accessed 26 Oct 2020].

20 Mbow M, Lell B, Jochems SP, et al. COVID-19 in Africa: dampening the storm? Science 2020;369:624-6.

21 Nordling L. Africa's pandemic puzzle: why so few cases and deaths? Science 2020;369:756-7.

22 Eelbode F. Africa is thriving in a corona pandemic [Internet], 2020. Available: https://www.tijd.be/politiek-economie/internationaal/ afrika/afrika-ontspringt-de-dans-in-coronapandemie/10245208.html [Accessed 02 Sep 2020].

23 Zhou F, Yu T, Du R, et al. Clinical course and risk factors for mortality of adult inpatients with COVID-19 in Wuhan, China: a retrospective cohort study. Lancet 2020;395:1054-62.

24 One million and counting - The covid-19 pandemic is worse than official figures show | Briefing | The Economist [Internet]. Available: https://www.economist.com/briefing/2020/09/26/the-covid-19pandemic-is-worse-than-official-figures-show [Accessed 22 Oct 2020].

25 World Population Prospects - Population Division - United Nations [Internet]. Available: https://population.un.org/wpp/ [Accessed 26 Oct 2020].

26 Musa $\mathrm{HH}$, Musa TH, Musa IH, et al. Addressing Africa's pandemic puzzle: perspectives on COVID-19 transmission and mortality in sub-Saharan Africa. Int J Infect Dis 2021;102:483-8.

27 CDC Weekly C. The epidemiological characteristics of an outbreak of 2019 novel coronavirus diseases (COVID-19) - China, 2020. China CDC Weekly 2020;2:113-22.

28 Prodotto dall'Istituto Superiore di Sanit (ISS) Roma. COVID-19 epidemic National update [Internet]. Prodotto dall'Istituto Superiore di Sanit (ISS), 2020. Available: https://www.epicentro.iss.it/ coronavirus/bollettino/Bollettino-sorveglianza-integrata-COVID-19_ 26-marzo\%202020.pdf [Accessed cited 2020 Jul 16].

29 Tinto B, Salinas S, Dicko A, et al. Spreading of SARS-CoV-2 in West Africa and assessment of risk factors. Epidemiol Infect 2020;148:e213.

30 Bamgboye EL, Omiye JA, Afolaranmi OJ, et al. COVID-19 pandemic: is Africa different? J Natl Med Assoc 2020. doi:10.1016/j. jnma.2020.10.001. [Epub ahead of print: 02 Nov 2020].

31 Lalaoui R, Bakour S, Raoult D, et al. What could explain the late emergence of COVID-19 in Africa? New Microbes New Infect 2020;38:100760

32 Nelde A, Bilich T, Heitmann JS, et al. SARS-CoV-2-derived peptides define heterologous and COVID-19-induced T cell recognition. Nat Immunol 2021;22:74-85.

33 Ministry of Health | Rwanda. 14.12.2020 Amakuru Mashya | Update COVID-19 [Internet]. Twitter, 2020. Available: https://twitter.com/ RwandaHealth/status/1338585377297354765/photo/1 [Accessed 15 Dec 2020]. 